\title{
Insulin Degludec Versus Insulin Glargine in Type 1 and Type 2 Diabetes Mellitus: A Meta-Analysis of Endpoints in Phase 3a Trials
}

\author{
Jiten Vora $\cdot$ Torsten Christensen $\cdot$ Azhar Rana $\cdot$ Steve C. Bain
}

To view enhanced content go to www.diabetestherapy-open.com

Received: June 11, 2014 / Published online: August 1, 2014

(C) The Author(s) 2014. This article is published with open access at Springerlink.com

\section{ABSTRACT}

Introduction: Insulin degludec (degludec) is a basal insulin with an ultra-long, stable action profile and reduced pharmacodynamic variability. Seven phase 3a trials compared degludec with insulin glargine (glargine). Patient-level meta-analyses were performed to

Electronic supplementary material The online version of this article (doi:10.1007/s13300-014-0076-9) contains supplementary material, which is available to authorized users.

J. Vora $(\square)$

Department of Diabetes and Endocrinology, Royal Liverpool University Hospitals, Prescot Street, Liverpool L7 8XP, UK

e-mail: jiten.vora@rlbuht.nhs.uk

T. Christensen

Health Economics, Novo Nordisk A/S, Søborg,

Denmark

A. Rana

Global Medical Affairs, Novo Nordisk A/S, Søborg,

Denmark

Present Address:

A. Rana

Clinical, Medical, Regulatory (CMR), Novo Nordisk

Canada Inc., Mississauga, Ontario, Canada

S. C. Bain

Department of Diabetes and Endocrinology,

Abertawe Bro Morgannwg University NHS Trust,

Swansea, UK obtain a comprehensive overview of differences between the insulin preparations, possible because consistent outcome definitions were utilized.

Methods: Three categories of trials were analyzed: basal-bolus-treated type 1 diabetes mellitus $\left(\mathrm{T}_{1} \mathrm{DM} \mathrm{B}_{\mathrm{B} / \mathrm{B}}\right)$, insulin-naïve type 2 diabetes mellitus (T2DM insulin-naive $_{\text {e }}$, and basalbolus-treated T2DM $\left(\mathrm{T}_{2} \mathrm{DM}_{\mathrm{B} / \mathrm{B}}\right)$. Regression models were adjusted for baseline characteristics. Endpoints analyzed were glycosylated hemoglobin $\left(\mathrm{HbA}_{1 \mathrm{c}}\right)$, fasting plasma glucose (FPG), insulin dose and hypoglycemic rates analyzed in mutually exclusive groups: non-severe nocturnal, nonsevere daytime, and severe.

Results: As with previous treat-to-target trials, reductions in $\mathrm{HbA}_{1 \mathrm{c}}$ were similar between degludec and glargine. Reductions in FPG were significantly greater with degludec in $\mathrm{T}_{1} \mathrm{DM}_{\mathrm{B} / \mathrm{B}}$ and $\mathrm{T}_{2} \mathrm{DM}_{\text {insulin-naïve }}$ Total daily insulin dose was significantly lower with degludec in $\mathrm{T}_{1} \mathrm{DM} \mathrm{B}_{\mathrm{B} / \mathrm{B}}$ and $\mathrm{T} 2 \mathrm{DM}_{\text {insulin-naive. }}$ Estimated hypoglycemia rate ratios for degludec/glargine were as follows for $\mathrm{T}_{1 \mathrm{DM}} \mathrm{B} / \mathrm{B}, \mathrm{T} 2 \mathrm{DM}_{\text {insulin-naïve }}$ and $\mathrm{T}_{2} \mathrm{DM}_{\mathrm{B} / \mathrm{B}}$, respectively: non-severe nocturnal $0.83,0.64,0.75$ (all $P<0.05$ ); non- 
severe daytime 1.14 [not significant (ns)], 0.89 (ns), and $0.83(P<0.05)$. Rate ratios for severe events were 1.12 (ns) $\left(\mathrm{T} 1 D M_{\mathrm{B} / \mathrm{B}}\right) ; 0.14(P<0.05)$ (T2DM $\left.\mathrm{D}_{\text {insulin-naive }}\right)$; and not analyzed $\left(\mathrm{T}_{2} \mathrm{DM}_{\mathrm{B} / \mathrm{B}}\right)$ due to too few events.

Conclusions: Compared with glargine, degludec is associated with equivalent $\mathrm{HbA}_{1 \mathrm{c}}$ control and significantly lower nocturnal hypoglycemia rates. In $\mathrm{T}_{1} \mathrm{DM}_{\mathrm{B} / \mathrm{B}}$ and $\mathrm{T}_{2} \mathrm{DM}_{\text {insulin-naïve, }}$ degludec is also associated with significantly greater reductions in FPG and lower total doses of insulin versus glargine.

Keywords: Fasting plasma glucose; Glycosylated hemoglobin $\left(\mathrm{HbA}_{1 \mathrm{c}}\right)$; Hypoglycemia; Insulin degludec; Insulin dose; Insulin glargine; Type 1 diabetes mellitus; Type 2 diabetes mellitus

\section{INTRODUCTION}

The need for effective glycemic control in type 1 (T1DM) and type 2 diabetes mellitus (T2DM) to prevent the development of complications is well understood. However, hypoglycemia and the fear of hypoglycemia, as well as weight gain, impair both patients' and physicians' willingness to titrate insulin to the doses required to achieve guideline-recommended target levels of glycemia [1-3]. With the two basal insulin analogs, insulin glargine (glargine) and insulin detemir (detemir), the risk of hypoglycemia is lower than with older human insulin formulations [4]. Nevertheless, there is still room for improvement in the pharmacokinetics and pharmacodynamics of basal insulin preparations, and consequently the search has continued for a basal analog with less variability in pharmacodynamic effect and a longer duration of action than those currently available to fulfil requirements in all patients with once-daily administration.
Insulin degludec (degludec) is a nextgeneration basal insulin with an ultra-long and stable action profile and lower pharmacodynamic variability than glargine [5, 6]. Degludec has been designed to form long, soluble multi-hexamer chains upon injection into the subcutaneous tissue; insulin monomers gradually dissociate from these [7]. This mechanism of protraction results in a flat and stable pharmacokinetic and pharmacodynamic profile [6]. Degludec has a half-life of approximately $25 \mathrm{~h}$ in patients with T2DM [6] and a glucose-lowering effect at steady state in patients with T1DM beyond $42 \mathrm{~h}$ [8].

The efficacy of degludec once daily was examined in a large clinical development program, BEGIN, which included nine 26- or 52-week trials. Three trials were versus glargine in basal-bolus therapy in T1DM $[9,10]$ and T2DM [11], and four trials were versus glargine in basal-oral therapy in T2DM [12-15]. In addition, degludec was compared with sitagliptin in a basal-oral trial in T2DM [16], and with detemir in a basal-bolus trial in T1DM. In all seven trials in which it was compared with glargine, degludec showed non-inferiority with respect to mean decrease in glycosylated hemoglobin $\left(\mathrm{HbA}_{1 \mathrm{c}}\right)$. Rates of confirmed hypoglycemia and, in particular, nocturnal confirmed hypoglycemia, were either similar with the two insulins or significantly lower with degludec. A pre-planned meta-analysis of hypoglycemia associated with the two treatments has already been published [17]. This meta-analysis confirmed that degludec is associated with a lower risk of hypoglycemia, in particular nocturnal confirmed hypoglycemia, compared with glargine. The reductions in hypoglycemia were even more marked in the maintenance period (i.e., after 16 weeks, when the initial up-titration was completed). Nocturnal hypoglycemia is a particularly 
useful outcome for reflecting differences between basal insulins, as it is less likely than daytime hypoglycemia to be confounded by the effect of bolus insulin, meals, and activity.

Previously, confirmed hypoglycemia included both severe and non-severe events. To avoid double counting of events in health economic models, the new meta-analyses reported here regrouped the confirmed events into three mutually exclusive groups: non-severe nocturnal, non-severe daytime, and severe hypoglycemia. The division of non-severe events into daytime and nocturnal was included to provide evidence on whether the documented reduction in nocturnal events with degludec was offset by a change in daytime events.

Individual studies also demonstrate a significantly or numerically lower insulin dose with degludec compared with glargine in T1DM $[9,10]$ and in T2DM [12-15]. In the new metaanalyses reported here, we investigated whether these findings could be confirmed.

Hypoglycemia and $\mathrm{HbA}_{1 \mathrm{c}}$ are the two endpoints generally considered of most interest when evaluating diabetes therapy. However, other endpoints such as fasting plasma glucose (FPG), insulin dose, and health-related quality of life (HRQoL) should also be considered to obtain a global view of the effectiveness of one therapy compared with another. Individual trials (in any field of medicine) are frequently under-powered to show significant differences in secondary endpoints, and meta-analysis is often required to reveal whether such differences exist. The BEGIN program was carefully designed with consistent definitions of outcomes across all trials, thus facilitating subsequent meta-analysis of the data.

This paper reports the results of a comprehensive set of patient-level meta-analyses that were performed to compare degludec and glargine with regard to $\mathrm{HbA}_{1 \mathrm{c}}$ (the primary endpoint in the trials), and hypoglycemia, FPG, and dose (secondary endpoints). The objective was to obtain a comprehensive overview of all relevant differences between degludec and glargine, adding to evidence on hypoglycemia [17] and HRQoL [18, 19].

\section{METHODS}

\section{Trials Included in the Meta-Analysis}

Table 1 lists all the trials in the BEGIN program that compared degludec once daily with glargine once daily and explains how they were categorized for the current meta-analysis. Some of the trials included in this analysis were randomized in a 2:1 or 3:1 manner. This unequal randomization is consequently reflected in the meta-analysis with more patients allocated to degludec than to glargine. Trials of degludec against insulin detemir and sitagliptin were not included in the meta-analysis as the purpose was to compare degludec against glargine.

The category $\mathrm{T}_{1} \mathrm{DM}_{\mathrm{B} / \mathrm{B}}(\mathrm{T} 1 \mathrm{DM}$ treated with basal-bolus therapy) included all patients from the BEGIN BB T1 Long (NCT00982228) and BEGIN Flex T1 (NCT01079234) trials [9, 10], except for patients in one degludec dosing arm in the BEGIN Flex T1 trial. Patients in the excluded arm received degludec at extreme ranges of daily dosing intervals, alternating dose time in the morning and evening; hence, inclusion of these data in the meta-analyses would be potentially confounding. The category $\mathrm{T}_{2} \mathrm{DM}_{\text {insulin-naïve }}$ included patients, all of whom were insulin-naïve, starting on basaloral therapy in the BEGIN Once Long (NCT00982644), BEGIN Once Asia (NCT01059799) and BEGIN Low Volume (NCT01068665) trials (U200) [12, 14, 15]. The BEGIN Flex trial (NCT01006291) in type 2 
Table 1 Phase 3a trials comparing insulin degludec once daily with insulin glargine once daily in the BEGIN program: categorization for the meta-analysis [9-15]

\begin{tabular}{|c|c|c|c|c|c|c|}
\hline $\begin{array}{l}\text { Trial } \\
\text { number }\end{array}$ & Trial name & References & $\begin{array}{l}\text { Meta-analysis } \\
\text { category }\end{array}$ & $\begin{array}{l}\text { Trial duration } \\
\text { (weeks) }\end{array}$ & $\begin{array}{l}\text { Patients } \\
\text { randomized }\end{array}$ & $\begin{array}{l}\text { Number of patients in } \\
\text { each arm }\end{array}$ \\
\hline 3583 & $\begin{array}{l}\text { BEGIN BB } \\
\text { T1 Long }\end{array}$ & [9] & $\mathrm{T} \mathrm{DM}_{\mathrm{B} / \mathrm{B}}$ & 52 & 629 & IDeg 472, IGlar 157 \\
\hline 3770 & $\begin{array}{l}\text { BEGIN Flex } \\
\mathrm{T}^{\mathrm{a}}\end{array}$ & {$[10]$} & $\mathrm{T} \mathrm{DM}_{\mathrm{B} / \mathrm{B}}$ & 26 & 493 & $\begin{array}{l}\text { IDeg FF 164, IDeg 165, } \\
\text { IGlar } 164\end{array}$ \\
\hline 3579 & $\begin{array}{l}\text { BEGIN Once } \\
\text { Long }\end{array}$ & {$[15]$} & $\mathrm{T}_{2} \mathrm{DM}_{\text {insulin-naïve }}$ & 52 & 1,030 & IDeg 773, IGlar 257 \\
\hline 3586 & $\begin{array}{l}\text { BEGIN Once } \\
\text { Asia }\end{array}$ & {$[14]$} & $\mathrm{T} 2 \mathrm{DM}_{\text {insulin-naive }}$ & 26 & 435 & IDeg 289, IGlar 146 \\
\hline 3672 & $\begin{array}{l}\text { BEGIN Low } \\
\text { Volume }\end{array}$ & {$[12]$} & $\mathrm{T}_{2} \mathrm{DM}_{\text {insulin-naïve }}$ & 26 & 460 & IDeg 230, IGlar 230 \\
\hline 3668 & BEGIN Flex ${ }^{\mathrm{b}}$ & {$[13]$} & Not included & 26 & 687 & $\begin{array}{l}\text { IDeg FF 229, IDeg 228, } \\
\text { IGlar } 230\end{array}$ \\
\hline 3582 & BEGIN BB & {$[11]$} & $\mathrm{T} 2 \mathrm{DM}_{\mathrm{B} / \mathrm{B}}$ & 52 & 1,006 & IDeg 755, IGlar 251 \\
\hline
\end{tabular}

$B B$ basal-bolus, $F F$ forced flexible, $T 1 D M_{B / B}$ basal-bolus-treated type 1 diabetes mellitus, $T 2 D M_{B / B}$ basal-bolus-treated type 2 diabetes mellitus, $T 2 D M_{\text {insulin-naive }}$ insulin-naïve type 2 diabetes mellitus

a Trial 3770 included a forced flexible-dosing arm with dosing intervals of 8 and $40 \mathrm{~h}$. This arm was excluded from the meta-analysis as the extreme fixed flexible-dosing intervals do not reflect the recommended use of insulin degludec in clinical practice

brial 3668 was excluded from the meta-analysis of $\mathrm{T} 2 \mathrm{DM}_{\text {insulin-naive }}$ as it included degludec used at extreme daily-dosing intervals and also patients treated with basal insulin at baseline

diabetes [13] was excluded from the metaanalysis as it included degludec used at extreme daily dosing intervals and also included patients already on insulin. One trial, BEGIN BB (NCT00972283) [11], compared degludec with glargine in basal-bolus therapy in $\mathrm{T} 2 \mathrm{DM}\left(\mathrm{T}_{2} \mathrm{DM} \mathrm{B}_{\mathrm{B} / \mathrm{B}}\right)$.

\section{Methodology of the Individual Phase 3a Trials}

All of the trials included in the current metaanalyses were randomized, treat-to-target, parallel-group, open-label, non-inferiority trials comparing degludec once daily with glargine once daily. All procedures followed in the trials were in accordance with the ethical standards of the responsible committee on human experimentation (institutional and national) and with the Helsinki Declaration of 1975, as revised in 2000 and 2008. Informed consent was obtained from all patients for being included in the studies. The analyses in this article do not involve any new studies of human or animal subjects performed by any of the authors.

The treat-to-target design was used, targeted at self-measured blood glucose $<5 \mathrm{mmol} / \mathrm{L}$, based on a mean of three consecutive days' measurements. Treating to a common target, recommended by the FDA [20], allows for interpretation of any between-treatment differences in the frequency and severity of hypoglycemia without being confounded by differences in glycemic control. The primary 
endpoint was the difference between treatment groups in the change in $\mathrm{HbA}_{1 \mathrm{c}}$ from baseline to study end. Non-inferiority was defined as an upper limit of $\leq 0.4 \%$ points for the $95 \%$ confidence interval for the treatment difference.

In all the trials (and for the purposes of metaanalysis), FPG measurements were performed in a central laboratory; hypoglycemia was selfreported; only confirmed hypoglycemic events (plasma glucose $<3.1 \mathrm{mmol} / \mathrm{L}$ or severe episodes requiring assistance) were included in the analyses; and nocturnal hypoglycemia was defined as episodes with onset from 00:01 to 05:59 am, inclusive.

\section{Statistical Analysis}

Meta-analyses were performed on patient-level data. The analyses examined the following endpoints: $\mathrm{HbA}_{1 \mathrm{c}}$, FPG, insulin dose, and hypoglycemia. A linear model was used to analyze $\mathrm{HbA}_{1 \mathrm{c}}$ and FPG. For insulin dose, the endpoint was log-transformed and analysis of variance (ANOVA) was used. Hypoglycemia was analyzed using a negative binomial regression model. Due to the low number of severe hypoglycemic episodes in $\mathrm{T}_{2} \mathrm{DM}_{\text {insulin-naive, }}$ this analysis was performed with a Poisson regression model using a log-link. The a priori level of significance was set as 0.05 and the statistical package used was SAS software version 9.4 (SAS Institute Inc., Cary, NC, USA). All the meta-analysis regression models were adjusted for trial, type of diabetes, antidiabetic therapy at screening, sex, region, and age. Except for hypoglycemia, all the models included baseline value as a covariate.

\section{RESULTS}

\section{Glycemic Control}

As expected in treat-to-target trials, there was no statistical difference between treatments in reducing $\mathrm{HbA}_{1 \mathrm{c}}$ : degludec was non-inferior to glargine in $\mathrm{T}_{1} \mathrm{DM}_{\mathrm{B} / \mathrm{B}}, \mathrm{T}_{2} \mathrm{DM}_{\text {insulin-naïve, and }}$

Table 2 Meta-analysis comparing insulin degludec once daily with insulin glargine once daily: $\mathrm{HbA}_{1 \mathrm{c}}$ and FPG [9-12, 14, 15]

\begin{tabular}{|c|c|c|c|c|c|c|c|}
\hline \multirow[t]{2}{*}{ Category } & \multirow[t]{2}{*}{ Trials } & \multicolumn{3}{|c|}{ Change in $\mathrm{HbA}_{1 \mathrm{c}}$ (\%-points): IDeg-IGlar } & \multicolumn{3}{|c|}{ Change in FPG $(\mathrm{mmol} / \mathrm{L})$ : IDeg-IGlar } \\
\hline & & $n$ (total) & Estimate & 95\% CI & $n$ (total) & Estimate & 95\% CI \\
\hline \multirow[t]{2}{*}{$\mathrm{T}_{1} \mathrm{DM} \mathrm{B}_{\mathrm{B} / \mathrm{B}}$} & 3583 & IDeg 637 & 0.06 & $-0.04 ; 0.15$ & IDeg 629 & $-0.61^{*}$ & $-1.13 ;-0.10$ \\
\hline & 3770 & IGlar 321 & & & IGlar 317 & & \\
\hline \multirow[t]{3}{*}{$\mathrm{T} 2 \mathrm{DM}_{\text {insulin-naïve }}$} & 3579 & IDeg 1,290 & 0.08 & $-0.01 ; 0.16$ & IDeg 1,278 & $-0.34^{*}$ & $-0.54 ;-0.15$ \\
\hline & 3586 & IGlar 632 & & & IGlar 627 & & \\
\hline & 3672 & & & & & & \\
\hline \multirow[t]{2}{*}{$\mathrm{T} 2 \mathrm{DM}_{\mathrm{B} / \mathrm{B}}$} & 3582 & IDeg 744 & 0.08 & $-0.05 ; 0.21$ & IDeg 740 & -0.29 & $-0.65 ; 0.06$ \\
\hline & & IGlar 248 & & & IGlar 248 & & \\
\hline
\end{tabular}

$C I$ confidence interval, $F P G$ fasting plasma glucose, $H b A_{1 c}$ glycosylated hemoglobin, IDeg insulin degludec, IGlar insulin glargine, $n$ number of patients, $T I D M_{B / B}$ basal-bolus-treated type 1 diabetes mellitus, $T 2 D M_{B / B}$ basal-bolus-treated type 2 diabetes mellitus, $T 2 D M_{\text {insulin-naive }}$ insulin-naïve type 2 diabetes mellitus

* Significant based on 95\% CI 
Table 3 Total daily insulin dose [basal + bolus (if relevant)] in $\mathrm{U} / \mathrm{kg}$ (adjusted for covariates ${ }^{\mathrm{a}}$ )

\begin{tabular}{llll}
\hline Category & IDeg & IGlar & $\begin{array}{l}\text { Estimated treatment } \\
\text { ratio }(95 \% \text { CI })^{\mathbf{a}}\end{array}$ \\
\hline $\mathrm{T} 1 \mathrm{DM}_{\mathrm{B} / \mathrm{B}}$ & $n=634$ & $n=314$ & \\
End of trial & $0.68 \mathrm{U} / \mathrm{kg}$ & $0.77 \mathrm{U} / \mathrm{kg}$ & $0.88^{* * *}(0.85 ; 0.92)$ \\
$\mathrm{T}_{2} \mathrm{DM}_{\text {insulin-naive }}$ & $n=1,267$ & $n=625$ & \\
End of trial & $0.39 \mathrm{U} / \mathrm{kg}$ & $0.43 \mathrm{U} / \mathrm{kg}$ & $0.90^{* *}(0.85 ; 0.96)$ \\
$\mathrm{T}^{\mathrm{DDM}} \mathrm{B}_{\mathrm{B} / \mathrm{B}}$ & $n=749$ & $n=249$ & \\
End of trial & $1.22 \mathrm{U} / \mathrm{kg}$ & $1.18 \mathrm{U} / \mathrm{kg}$ & $1.03(0.97 ; 1.10)$ \\
\hline
\end{tabular}

Data are observed mean and week 52 values are presented with the LOCF approach

ANOVA analysis of variance, CI confidence interval, $L O C F$ last observation carried forward, IDeg insulin degludec, IGlar insulin glargine, $n$ number of patients, $T 1 D M_{B / B}$ basal-bolus-treated type 1 diabetes mellitus, $T 2 D M_{B / B}$ basal-bolus-treated type 2 diabetes mellitus, $T 2 D M_{\text {insulin-naive }}$ insulin-naïve type 2 diabetes mellitus

${ }^{* *} P=0.0004 ;{ }^{* * *} P<0.0001$

${ }^{a}$ Estimated using ANOVA with treatment, sex, antidiabetic therapy at screening, age, and baseline dose as covariates

$\mathrm{T}_{2} \mathrm{DM}_{\mathrm{B} / \mathrm{B}}$ (Table 2). These results confirmed the non-inferiority documented in each individual trial.

End-of-trial reduction in FPG was significantly greater with degludec than with glargine in $\mathrm{T}_{1} \mathrm{DM} \mathrm{B}_{\mathrm{B} / \mathrm{B}}$ and $\mathrm{T}_{2} \mathrm{DM}_{\text {insulin-naïve }}$ $(P<0.05)$, and numerically (but not significantly) greater in $\mathrm{T}_{2} \mathrm{DM}_{\mathrm{B} / \mathrm{B}}$ (Table 2).

\section{Insulin Dose}

In $\mathrm{T}_{1 \mathrm{DM}} \mathrm{M}_{\mathrm{B} / \mathrm{B}}$, the total daily dose of insulin was significantly lower, by $12 \%$, with degludec compared with glargine $(P<0.0001)$ (Table 3$)$. Statistical analyses were performed for both basal and bolus insulin doses to clarify the relative contribution of each to the observed reduction in total dose. These showed that the daily basal and bolus doses were both lower with degludec, with relative rates (degludec versus glargine) as follows: daily basal dose, 0.87; daily bolus dose, 0.88 (both $P<0.05$ ).

The total daily insulin dose was also significantly lower (by 10\%, $P=0.0004$ ) with

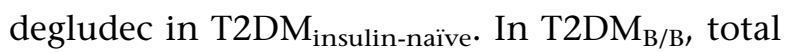

daily insulin dose did not differ statistically between treatments (Table 3 ).

\section{Hypoglycemia Analyzed in Mutually Exclusive Groups}

The actual event rates for the mutually exclusive groups used in the current metaanalysis are shown in Table 4 . Event rates for the individual trials are available in the earlier papers [11, 17]. The estimated hypoglycemia rate ratios for the current meta-analysis are shown in Table 5. These results showed significantly lower rates of nocturnal nonsevere hypoglycemia with degludec in $\mathrm{T} \mathrm{DM}_{\mathrm{B} /}$

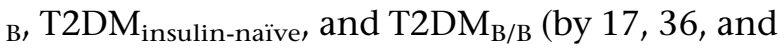
25\%, respectively; all $P<0.05)$. With degludec, rates of daytime non-severe hypoglycemia were significantly lower than with glargine (by 17\%; $P<0.05)$ in $\mathrm{T}_{2} \mathrm{DM}_{\mathrm{B} / \mathrm{B}}$, with no statistical differences in $\mathrm{T}_{1} \mathrm{DM}_{\mathrm{B} / \mathrm{B}}$ and $\mathrm{T} 2 \mathrm{DM}_{\text {insulin-naive }}$ Rate ratios for severe events, analyzed in the previous meta-analysis (and not re-analyzed, as the definition remained unchanged) [17], were 1.12 [not significant (ns)] $\left(\mathrm{T}_{1} \mathrm{DM}_{\mathrm{B} / \mathrm{B}}\right) ; 0.14$ 
Table 4 Observed daytime and nocturnal non-severe hypoglycemic events in the current meta-analysis $[9-12,14,15]$

\begin{tabular}{|c|c|c|c|c|c|}
\hline \multirow[t]{2}{*}{ Category } & \multirow[t]{2}{*}{ Trials } & \multicolumn{2}{|c|}{ Daytime non-severe } & \multicolumn{2}{|c|}{ Nocturnal non-severe } \\
\hline & & $\overline{n \text { (total) }}$ & $\overline{\text { Events/PYE }}$ & $\overline{n(\text { total })}$ & $\overline{\text { Events/PYE }}$ \\
\hline \multirow[t]{2}{*}{$\mathrm{T} 1 \mathrm{DM}_{\mathrm{B} / \mathrm{B}}$} & \multirow[t]{2}{*}{3583 and 3770} & IDeg 608 & IDeg 44.02 & IDeg 458 & IDeg 5.13 \\
\hline & & IGlar 300 & IGlar 46.62 & IGlar 230 & IGlar 7.23 \\
\hline \multirow[t]{2}{*}{$\mathrm{T} 2 \mathrm{DM}_{\text {insulin-naïe }}$} & \multirow[t]{2}{*}{3579,3586 and 3672} & IDeg 498 & IDeg 1.38 & IDeg 178 & IDeg 0.32 \\
\hline & & IGlar 235 & IGlar 1.54 & IGlar 94 & IGlar 0.51 \\
\hline \multirow[t]{2}{*}{$\mathrm{T} 2 \mathrm{DM}_{\mathrm{B} / \mathrm{B}}$} & \multirow[t]{2}{*}{3582} & IDeg 593 & IDeg 9.67 & IDeg 295 & IDeg 1.37 \\
\hline & & IGlar 201 & IGlar 11.75 & IGlar 119 & IGlar 1.83 \\
\hline
\end{tabular}

IDeg insulin degludec, IGlar insulin glargine, $n$ number of patients, PYE patient-year of exposure, $T I D M_{B / B}$ basal-bolustreated type 1 diabetes mellitus, $T 2 D M_{B / B}$ basal-bolus-treated type 2 diabetes mellitus, $T 2 D M_{\text {insulin-naive }}$ insulin-naïve type 2 diabetes mellitus

Table 5 Hypoglycemia rate ratios in the current meta-analysis during the full trial period, and in the maintenance period

\begin{tabular}{|c|c|c|c|c|c|c|c|}
\hline \multirow[t]{3}{*}{ Category } & \multirow[t]{3}{*}{ Trials } & \multicolumn{3}{|c|}{ Full trial period ${ }^{a}$} & \multicolumn{3}{|c|}{ Maintenance period ${ }^{b}$} \\
\hline & & \multirow[t]{2}{*}{$\overline{n \text { (total) }}$} & \multicolumn{2}{|c|}{$\begin{array}{l}\text { Estimated rate ratio IDeg/ } \\
\text { IGlar }(95 \% \mathrm{CI})\end{array}$} & \multirow[t]{2}{*}{$n$ (total) } & \multicolumn{2}{|c|}{$\begin{array}{l}\text { Estimated rate ratio IDeg/ } \\
\text { IGlar }(95 \% \mathrm{CI})\end{array}$} \\
\hline & & & $\begin{array}{l}\text { Daytime } \\
\text { non-severe }\end{array}$ & $\begin{array}{l}\text { Nocturnal } \\
\text { non-severe }\end{array}$ & & $\begin{array}{l}\text { Daytime } \\
\text { non-severe }\end{array}$ & $\begin{array}{l}\text { Nocturnal } \\
\text { non-severe }\end{array}$ \\
\hline \multirow[t]{2}{*}{$\mathrm{T} 1 \mathrm{DM}_{\mathrm{B} / \mathrm{B}}$} & $\begin{array}{l}3583 \text { and } \\
3770\end{array}$ & $\begin{array}{r}\text { IDeg } \\
637\end{array}$ & $\begin{array}{l}1.14 \\
(0.99 ; 1.31)\end{array}$ & $\begin{array}{l}0.83^{*} \\
(0.69 ; 0.99)\end{array}$ & $\begin{array}{r}\text { IDeg } \\
596\end{array}$ & $\begin{array}{l}1.06 \\
(0.91 ; 1.25)\end{array}$ & $\begin{array}{l}0.75^{*} \\
(0.60 ; 0.94)\end{array}$ \\
\hline & & $\begin{array}{r}\text { IGlar } \\
321\end{array}$ & & & $\begin{array}{r}\text { IGlar } \\
303\end{array}$ & & \\
\hline \multirow[t]{2}{*}{$\mathrm{T} \mathrm{DM}_{\text {insulin-naïve }}$} & $\begin{array}{r}3579,3586 \\
\text { and } 3672\end{array}$ & $\begin{array}{l}\text { IDeg } \\
1,290\end{array}$ & $\begin{array}{l}0.89 \\
(0.75 ; 1.07)\end{array}$ & $\begin{array}{l}0.64^{*} \\
(0.47 ; 0.86)\end{array}$ & $\begin{array}{l}\text { IDeg } \\
1,152\end{array}$ & $\begin{array}{l}0.80^{*} \\
(0.64 ; 1.00)\end{array}$ & $\begin{array}{l}0.51^{*} \\
(0.36 ; 0.72)\end{array}$ \\
\hline & & $\begin{array}{r}\text { IGlar } \\
632\end{array}$ & & & $\begin{array}{r}\text { IGlar } \\
575\end{array}$ & & \\
\hline \multirow[t]{3}{*}{$\mathrm{T} 2 \mathrm{DM}_{\mathrm{B} / \mathrm{B}}$} & 3582 & $\begin{array}{r}\text { IDeg } \\
753\end{array}$ & $\begin{array}{l}0.83^{*} \\
(0.69 ; 0.99)\end{array}$ & $\begin{array}{l}0.75^{*} \\
(0.57 ; 0.98)\end{array}$ & $\begin{array}{r}\text { IDeg } \\
677\end{array}$ & $\begin{array}{l}0.84 \\
(0.68 ; 1.03)\end{array}$ & $\begin{array}{l}0.71^{*} \\
\quad(0.51 ; 0.99)\end{array}$ \\
\hline & & IGlar & & & IGlar & & \\
\hline & & 251 & & & 233 & & \\
\hline
\end{tabular}

CI confidence interval, $I D e g$ insulin degludec, IGlar insulin glargine, $n$ number of patients, $T I D M_{B / B}$ basal-bolus-treated type 1 diabetes mellitus, $T 2 D M_{B / B}$ basal-bolus-treated type 2 diabetes mellitus, $T 2 D M_{\text {insulin-naive }}$ insulin-naïve type 2 diabetes mellitus

* Significant based on $95 \%$ CI

a 'Nocturnal' in the previously published analysis included all nocturnal events, severe and non-severe. In the current metaanalysis, three mutually exclusive groups were defined: non-severe nocturnal, non-severe daytime and severe hypoglycemia. The definition of, and results for, severe episodes were similar in both analyses; therefore, severe episodes are not included in the current meta-analysis

b Same assumptions as above. The maintenance period is from week 16 and onwards 
$(P<0.05)\left(\mathrm{T}_{2} \mathrm{DM}_{\text {insulin-naïve }}\right)$; and not analyzed $\left(\mathrm{T}_{2} \mathrm{DM}_{\mathrm{B} / \mathrm{B}}\right)$ due to too few events. Rate ratios for daytime and nocturnal non-severe events in the full trial and maintenance (week 16 onwards) periods are shown in Table 5.

\section{DISCUSSION}

This meta-analysis showed that across subgroups of patients with diabetes, those treated with degludec achieve similar or significantly better results than those treated with glargine in terms of FPG and rates of hypoglycemia, with similar reductions in $\mathrm{HbA}_{1 \mathrm{c}}$. These results are achieved with lower mean total insulin doses.

Non-inferiority of degludec with respect to $\mathrm{HbA}_{1 \mathrm{c}}$ lowering was confirmed (Table 2). Noninferiority is expected for treat-to-target trials and was indeed seen in each trial. Nevertheless, it is useful to confirm that, across different subgroups, based on patient-level data, the lower rates of hypoglycemia seen with degludec are not obtained at a cost of inferior glycemic control.

The individual trials had shown numerically $[9,11,14]$ or significantly greater reductions in FPG [12, 15] with degludec. The current metaanalysis showed significantly greater reductions in FPG at trial end with degludec in both $\mathrm{T}_{1} \mathrm{DM}_{\mathrm{B} / \mathrm{B}}$ and $\mathrm{T} 2 \mathrm{DM}_{\text {insulin-naïve }}(0.61$ and $0.34 \mathrm{mmol} / \mathrm{L}$, respectively) (Table 2).

In the current meta-analysis of hypoglycemia analyzed in mutually exclusive groups (Table 4), rates of confirmed hypoglycemia in T2DM were low and were generally in line with rates observed in other trials. For example, among insulin-naïve patients, the non-severe confirmed hypoglycemia rates with glargine were 2.05 and 3.0 events per patient-year, respectively, in the current meta-analysis (Table 4) and in the treat- to-target trial (which used a similar definition, with confirmed events of $\leq 3.1 \mathrm{mmol} / \mathrm{L}$ ) [21]. Corresponding nocturnal events were 0.51 and 1.3 per patient-year, respectively.

It is striking that despite the low hypoglycemic event rates observed in trials, in the current meta-analysis, rates of nocturnal non-severe hypoglycemia were significantly lower with degludec than with glargine in all subgroups (Table 5). Rates of daytime nonsevere hypoglycemia were numerically lower in $\mathrm{T}_{2} \mathrm{DM}_{\text {insulin-naive }}$ and significantly lower in $\mathrm{T}_{2} \mathrm{DM}_{\mathrm{B} / \mathrm{B}}$ with degludec (Table 5). Thus, the lower rates of nocturnal non-severe events observed with degludec do not occur at a cost of higher daytime rates in T2DM. In $\mathrm{T}^{\mathrm{DDM}} \mathrm{B}_{\mathrm{B} / \mathrm{B}}$, daytime non-severe rates were numerically but not statistically higher with degludec (Table 5). These results may have been confounded by the unequal dose adjustment in the $\mathrm{T} \mathrm{DM}_{\mathrm{B} / \mathrm{B}}$ trials for patients randomized from twice-daily (BID) insulin. For patients previously on BID insulin who were randomized to glargine, a $20-30 \%$ reduction in starting dose was recommended, whereas patients randomized to degludec maintained the same dose. This possibility is further supported by the fact that during the predefined maintenance phase ( $>16$ weeks), there was no increase in the risk of daytime non-severe hypoglycemia with degludec.

Furthermore, these lower rates of nocturnal non-severe hypoglycemia with degludec were observed together with significantly or numerically greater reductions in FPG values. Lower FPG values would normally be expected to be accompanied by higher rates of nocturnal hypoglycemia, but with degludec, the reverse was observed. This can most likely be attributed to the stable and consistent profile of degludec, with its long duration of action and lower dayto-day pharmacodynamic variability compared with glargine $[5,6]$. 
Hypoglycemia and fear of hypoglycemia remain barriers to achieving target levels of control [3]. In addition, hypoglycemia has negative health-economic consequences such as additional contacts with healthcare professionals and absence from work following an event, and these are particularly marked for nocturnal hypoglycemia [22]. The possibility of achieving lower FPG together with lower risk of nocturnal hypoglycemia with degludec is, therefore, valuable both to patients and in terms of overall costs.

The value to patients of the lower risk of hypoglycemia can be expressed in terms of numbers needed to treat, as reported previously [17]. In $\mathrm{T}_{2} \mathrm{DM}_{\text {insulin-naïve, for every } 100 \text { people }}$ treated with degludec instead of glargine for 1 year, 50 confirmed hypoglycemic episodes (of which 20 are nocturnal) and two severe episodes will be avoided. In $\mathrm{T}_{2} \mathrm{DM}_{\mathrm{B} / \mathrm{B}}$, for every 100 people treated with degludec instead of glargine for 1 year, 326 confirmed hypoglycemic episodes (of which 71 are nocturnal) will be avoided. In $\mathrm{T}_{1} \mathrm{DM}_{\mathrm{B} / \mathrm{B}}$, for every 100 subjects treated with degludec instead of glargine for 1 year, 130 nocturnal confirmed episodes will be avoided once the initial titration phase has been completed.

These results are unlikely to have arisen through bias. The trials in the BEGIN program were open-label because blinding of treatment would have been extremely difficult, given the different insulin-delivery devices used. This open-label design could have given rise to a reporting bias in the patient-reported outcomes of hypoglycemia, which would constitute a limitation of the current study. There is no reason to believe that such a bias was present, and the requirement for patients to report only confirmed episodes of hypoglycemia should have limited any subjective influences. Furthermore, the same titration algorithm was used consistently across all trials for both basal insulins to ensure that differences in titration would not confound results.

Glargine was given according to its product labeling (i.e., administered at any time of day as advised by the investigator, at the same time each day), whereas degludec was administered once daily with the main evening meal, except in BEGIN Once Asia, where it could be given from the start of the evening meal to bedtime. However, any effect of possible different timing of administration of the two insulins is unlikely to change the conclusions of the meta-analysis. If glargine had systematically been given earlier in the day than degludec, nocturnal hypoglycemia would have been expected to be lower with glargine. If, on the other hand, it had been given later than degludec, any increase in nocturnal hypoglycemia should have been accompanied by greater decreases in FPG with glargine.

End-of-trial total daily insulin doses were significantly lower with degludec versus glargine in $\mathrm{T}_{1} \mathrm{DM} \mathrm{M}_{\mathrm{B} / \mathrm{B}}$ and $\mathrm{T}_{2} \mathrm{DM}_{\text {insulin-naïve }}$ (Table 3). This observation of lower doses with degludec confirms the findings from individual trials, with significantly lower end-of-trial mean total insulin doses as follows: in $\mathrm{T}^{\mathrm{DDM}} \mathrm{M}_{\mathrm{B} / \mathrm{B}}, 11 \%$ lower in both the BEGIN BB T1 Long trial $(P<0.001)$ [9] and in the BEGIN Flex T1 trial (statistical significance not reported) [10]; and in T2DM $\mathrm{M}_{\text {insulin-naive, }} 20 \%$ lower in BEGIN Once Asia $(P=0.0004)[14]$ and $11 \%$ lower in BEGIN Low Volume $(P<0.05)$ [12]. In the third $\mathrm{T}_{2} \mathrm{DM}_{\text {insulin-naive }}$ trial, BEGIN Once Long [15], mean end-of-trial doses were not statistically different for degludec and glargine.

With the exception of BEGIN Flex T1, HRQoL was measured in all of the trials included in this meta-analysis using the SF-36 questionnaire [23], which patients completed themselves. As HRQoL results have already been 
published, HRQoL was not included in the current meta-analysis. For $\mathrm{T}_{1 \mathrm{DM}} \mathrm{B} / \mathrm{B}$, there were no significant between-treatment differences in change from baseline in HRQoL in the BEGIN BB T1 Long trial [9]. For $\mathrm{T}_{2} \mathrm{DM}_{\text {insulin-naïve, a }}$ meta-analysis examining HRQoL changeswhich included BEGIN Once Long, BEGIN Once Asia and BEGIN Low Volume-reported that, at endpoint, the overall physical health component score was significantly better with degludec versus glargine, due primarily to a better score for degludec in the bodily pain domain [19]. In the mental domains, the vitality score was significantly better with degludec. For $\mathrm{T}_{2} \mathrm{DM}_{\mathrm{B} / \mathrm{B}}$, HRQoL scores were significantly better with degludec for the domain of bodily pain [11]. A further metaanalysis evaluated HRQoL expressed in terms of health utility score (a value for estimating quality of life) across all six BEGIN trials in which HRQoL was measured [18]. Degludec was associated with a modest but statistically significant improvement in health utility compared with glargine.

\section{CONCLUSIONS}

Compared with glargine, degludec is associated with equivalent $\mathrm{HbA}_{1 \mathrm{c}}$ control and significantly lower nocturnal hypoglycemia rates. In patients with T1DM and insulin-naïve patients with T2DM, degludec is also associated with significantly greater reductions in FPG versus glargine. Patients with T1DM and insulin-naïve patients with T2DM also required lower total doses of insulin and all groups reported improvements in HRQoL. It is possible that these advantages-in particular, efficacious lowering of FPG values together with lower rates of nocturnal hypoglycemia-could encourage physicians and patients to titrate insulin regimens more rigorously to reach glycemic target values.

\section{ACKNOWLEDGMENTS}

This meta-analysis was based on trials sponsored by Novo Nordisk A/S (Bagsværd, Denmark). Sponsorship and article processing charges for this study were funded by Novo Nordisk A/S.

Conflict of interest. Jiten Vora has participated in advisory boards for Novo Nordisk, Eli Lilly, Sanofi, MSD, Boehringer Ingelheim, Bristol-Myers Squibb, Novartis and Abbott; has received research support from Novo Nordisk, MSD, Eli Lilly and Sanofi; and has participated in speakers' bureaus for Novo Nordisk, Eli Lilly, Sanofi, MSD, Novartis, Abbott and Boehringer Ingelheim. Torsten Christensen is an employee of Novo Nordisk A/S and owns stocks/shares in the company. Azhar Rana is an employee of Novo Nordisk A/S and owns stocks/ shares in the company. Steve C Bain has participated in advisory boards for AstraZeneca, Boehringer Ingelheim, BristolMyers Squibb, Diartis, Eli Lilly, MSD, Novo Nordisk, Omnia-Med and Sanofi; and is a board member of Glycosmedia.

Compliance with ethics guidelines. The analyses in this article are based on previously conducted studies and do not involve any new studies of human or animal subjects performed by any of the authors.

Open Access. This article is distributed under the terms of the Creative Commons Attribution Noncommercial License which permits any noncommercial use, distribution, 
and reproduction in any medium, provided the original author(s) and the source are credited.

\section{REFERENCES}

1. Cryer PE. Hypoglycaemia: the limiting factor in the glycaemic management of type I and type II diabetes. Diabetologia. 2002;45:937-48.

2. Graveling AJ, Frier BM. Hypoglycaemia: an overview. Prim Care Diabetes. 2009;3:131-9.

3. Leiter LA, Yale J-F, Chiasson J-L, Harris SB, Kleinstiver P, Sauriol L. Assessment of the impact of fear of hypoglycemic episodes on glycemic and hypoglycemic management. Can J Diabetes. 2005;29:186-92.

4. Horvath K, Jeitler K, Berghold A, et al. Long-acting insulin analogues versus NPH insulin (human isophane insulin) for type 2 diabetes mellitus. Cochrane Database Syst Rev. 2007;(2):CD005613.

5. Heise T, Hermanski L, Nosek L, Feldman A, Rasmussen $\mathrm{S}$, Haahr $\mathrm{H}$. Insulin degludec: four times lower pharmacodynamic variability than insulin glargine under steady-state conditions in type 1 diabetes. Diabetes Obes Metab. 2012;14:859-64.

6. Heise T, Nosek L, Bøttcher SG, Hastrup H, Haahr H. Ultra-long-acting insulin degludec has a flat and stable glucose-lowering effect in type 2 diabetes. Diabetes Obes Metab. 2012;14:944-50.

7. Jonassen I, Havelund S, Hoeg-Jensen T, Steensgaard DB, Wahlund PO, Ribel U. Design of the novel protraction mechanism of insulin degludec, an ultra-long-acting basal insulin. Pharm Res. 2012;29:2104-14.

8. Kurtzhals P, Heise T, Strauss HM, et al. Multihexamer formation is the underlying mechanism behind the ultra-long glucose-lowering effect of insulin degludec. Diabetes. 2011;60(Suppl 1):LB12 (abstract 42-LB).

9. Heller S, Buse J, Fisher M, et al. Insulin degludec, an ultra-longacting basal insulin, versus insulin glargine in basal-bolus treatment with mealtime insulin aspart in type 1 diabetes (BEGIN Basal-Bolus Type 1): a phase 3, randomised, open-label, treat-totarget non-inferiority trial. Lancet. 2012;379:1489-97.

10. Mathieu C, Hollander P, Miranda-Palma B, et al. Efficacy and safety of insulin degludec in a flexible dosing regimen vs insulin glargine in patients with type 1 diabetes (BEGIN: Flex T1): a 26-week randomized, treat-to-target trial with a 26-week extension. J Clin Endocrinol Metab. 2013;98:1154-62.

11. Garber $A J$, King $A B$, Del Prato $S$, et al. Insulin degludec, an ultra-longacting basal insulin, versus insulin glargine in basal-bolus treatment with mealtime insulin aspart in type 2 diabetes (BEGIN Basal-Bolus Type 2): a phase 3, randomised, openlabel, treat-to-target non-inferiority trial. Lancet. 2012;379:1498-507.

12. Gough SC, Bhargava A, Jain R, Mersebach $H$, Rasmussen S, Bergenstal RM. Low-Volume Insulin Degludec 200 Units/mL once daily improves glycemic control similarly to insulin glargine with a low risk of hypoglycemia in insulin-naive patients with type 2 diabetes: a 26-week, randomized, controlled, multinational, treat-to-target trial: The BEGIN Low Volume trial. Diabetes Care. 2013;36:2536-42.

13. Meneghini L, Atkin SL, Gough SC, et al. The efficacy and safety of insulin degludec given in variable once-daily dosing intervals compared with insulin glargine and insulin degludec dosed at the same time daily: a 26-week, randomized, openlabel, parallel-group, treat-to-target trial in people with type 2 diabetes. Diabetes Care. 2013;36:858-64.

14. Onishi Y, Iwamoto Y, Yoo SJ, Clauson P, Tamer SC, Park S. Insulin degludec compared with insulin glargine in insulin-naïve patients with type 2 diabetes: a 26-week, randomized, controlled, PanAsian, treat-to-target trial. J Diabetes Invest. 2013;4:605-12.

15. Zinman B, Philis-Tsimikas A, Cariou B, et al. Insulin degludec versus insulin glargine in insulin-naive patients with type 2 diabetes: a 1-year, randomized, treat-to-target trial (BEGIN Once Long). Diabetes Care. 2012;35:2464-71.

16. Philis-Tsimikas A, Del Prato S, Satman I, et al. Effect of insulin degludec versus sitagliptin in patients with type 2 diabetes uncontrolled on oral antidiabetic agents. Diabetes Obes Metab. 2013;15:760-6.

17. Ratner RE, Gough SC, Mathieu C, et al. Hypoglycaemia risk with insulin degludec compared with insulin glargine in type 2 and type 1 diabetes: a pre-planned meta-analysis of phase 3 trials. Diabetes Obes Metab. 2013;15:175-84.

18. Freemantle N, Evans M, Christensen T, Wolden ML, Bjorner JB. A comparison of health-related quality of life (health utility) between insulin degludec and insulin glargine: a meta-analysis of phase 3 trials. Diabetes Obes Metab. 2013;15:564-71. 
19. Freemantle N, Meneghini L, Christensen T, Wolden $\mathrm{ML}$, Jendle J, Ratner R. Insulin degludec improves health-related quality of life (SF-36(R)) compared with insulin glargine in people with type 2 diabetes starting on basal insulin: a meta-analysis of phase 3a trials. Diabet Med. 2013;30:226-32.

20. US Department of Health and Human Services FaDACfDEaR, US Department of Health and Human Services, Food and Drug Administration Center for Drug Evaluation and Research (CDER). Guidance for industry: diabetes mellitus: developing drugs and therapeutic biologies for treatment and prevention (draft guidance). 2008.

21. Riddle MC, Rosenstock J, Gerich J, Insulin Glargine 4002 Study Investigators. The treat-to-target trial: randomized addition of glargine or human NPH insulin to oral therapy of type 2 diabetic patients. Diabetes Care. 2003;26:3080-6.

22. Brod M, Christensen T, Bushnell DM. Impact of nocturnal hypoglycemic events on diabetes management, sleep quality, and next-day function: results from a four-country survey. J Med Econ. 2012;15:77-86.

23. Ware JE, Kosinski M, Bjorner JB, Turner-Bowker DM, Gandek B, Maruish ME. User's manual for the SF-36v2 health survey. 2nd ed. Lincoln: QualityMetric Inc; 2007. 